\title{
Research on Interlayer water injection pressure limit
}

\section{SunYaliang}

\section{No.5 Oil-Extraction of Daqing Oilfield Company Ltd; Daqing 163513; China}

Keywords: Interlayer; Water injection pressure limit;Casing damage

Abstract: With the development of oil field into the late period of high water cut, the influence of casing damage on oil field development attracts more and more attention.So it's time to begin studying how to prevent and control casing damage. In the non oil layer casing damage well, $49.7 \%$ in A - B Interlayer of casing damage, and it is widely distributed in the SII block. At the same time, it seriously affect the development effect of upper reservoir in SII formation. In this paper, in view of the interlayer lithology recognition, analyze its mechanism of casing damage and discuss the reasonable limit of water injection pressure for casing damage control.

\section{Interlayer lithologycharacteristic}

From the observation of the actualcore of thislayer: $\mathrm{A}$ and $\mathrm{B}$ interlayer are widely distributed in $\mathrm{X}$ Development Zone, the thickness is about 10 meters, It contains two lines of oil shale about $3 \mathrm{~cm}$ thick in the lower part. According to the characteristics of the rock it can be divided into two parts ${ }^{[1-3]}$. Through the detailed observation, contrast analysis we found that: although the upper and lower rock are the massive shale, but mineralogy characteristics, fossil content, and the rock bedding and a significant difference between the fracture development aspect, lower fossil-rich, but relatively less than N2 standard fossil layers.

\section{2 geologic model of casing damage of A - B interlayer}

Casing damage mechanism and geological model: c Combined with the core observation and logging curves and the results of fluorescence, we found out the characteristics of mudstone in the lower part of the A-B interlayer have the characteristics of hard lithology, Thus, when the rock is subjected to shear stress, the stress is released along the weak surface of the fossil layer, it can lead to casing damage $\mathrm{e}^{[4-6]}$.

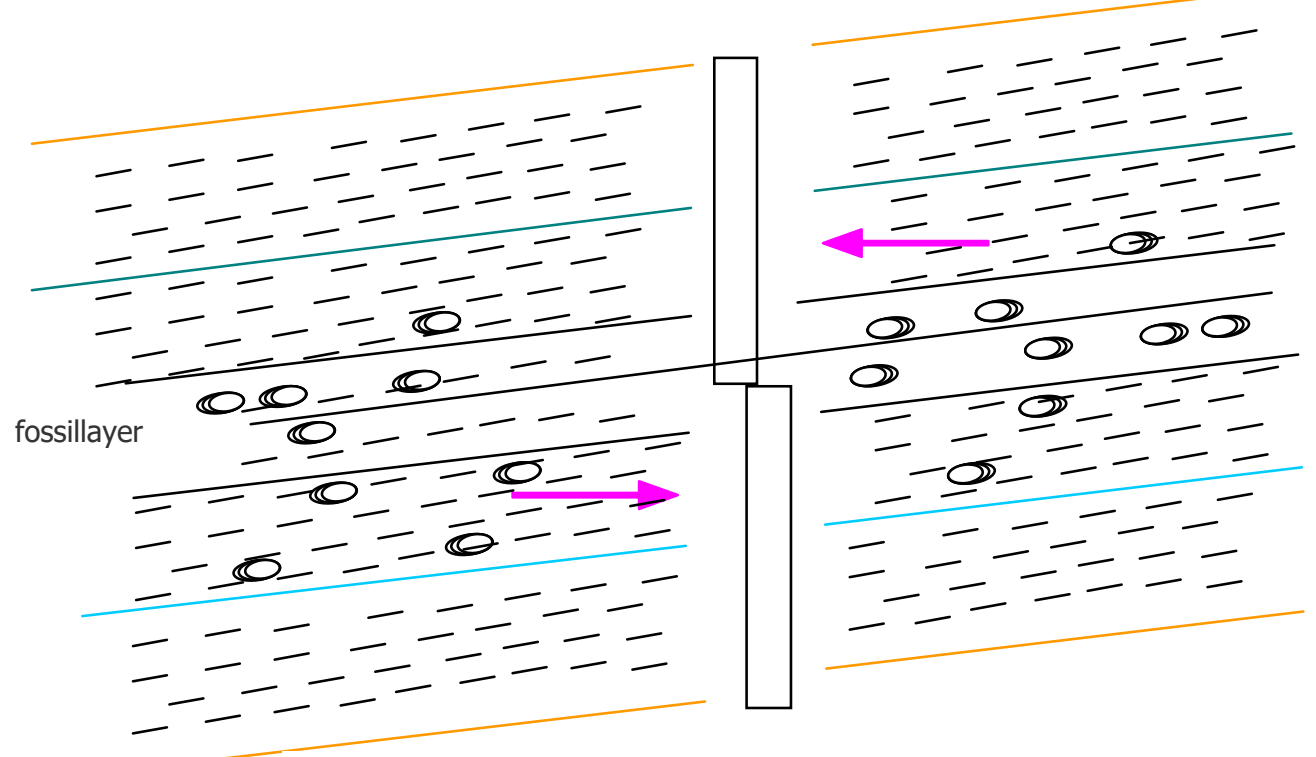

Fig.1geologic model of casing damage of A - B interlayer

\section{3 mechanical mechanism of casing damage of $A$ - $B$ interlayer}

According to the characteristics and geological characteristics of the apricot southern oilfield casing damage model, we established the shear mechanics model of casing damage and the model considering the vertical principal stress value, the maximum principal stress, the level of minimum principal stress value, direction of 
maximum principal stress and formation strength, cohesion, internal friction Angle), formation and fault occurrence (dip Angle and tendency) ${ }^{[7]}$.

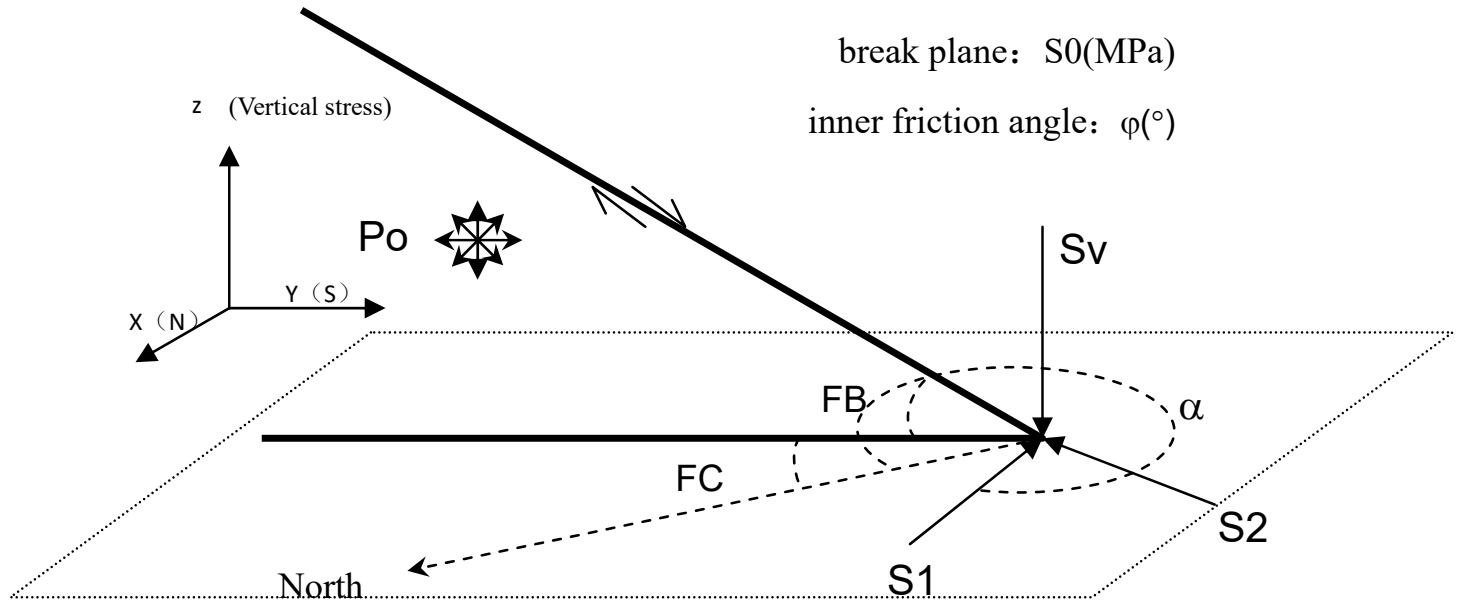

Fig.2shear mechanical model of casing damage under the action of crustal stress

(1) The horizontal maximum principal stress: S1(MPa); The horizontal minimum principal stress: S2(MPa); The vertical stress: $\operatorname{Sv}(\mathrm{MPa})$; The direction of the horizontal maximum principal stress: $\alpha\left(^{\circ}\right), \alpha\left(^{\circ}\right)$ In the form of azimuth, the starting point is the geographic north, clockwise to the Angle of the horizontal maximum principal stress direction $(0 \leqslant \alpha \leqslant 180)$ 。

(2) Pressure of pore water: $\mathrm{PO}(\mathrm{MPa})$ 。

(3) Dip direction: $F C\left({ }^{\circ}\right)$ In the form of azimuth, the starting point is the geographic north, clockwise turn to dip direction Angle $(0 \leqslant \mathrm{FC} \leqslant 360)$ 。Fault or dip: $\mathrm{FB}\left(^{\circ}\right)$ Angle between the fault plane and horizontal plane, the vertical is $90^{\circ}$, the horizontal is $0^{\circ}(0 \leqslant \mathrm{FB} \leqslant 90)$ 。

(4) The strength of the formation properties: cohesion: S0(MPa); inner friction angle: $\varphi\left({ }^{\circ}\right)$ 。 These two parameters varies with shale hydration。

(5) $S_{i j}$ :principal stress under the coordinate system of the stress tensor

$S_{i j}$ 'the main geographical coordinates of the stress tensor

$C s_{i j}$ : The direction cosine

Under the principal stress coordinate system

$$
\begin{aligned}
& S_{11}=S_{1} \quad S_{22}=S_{2} \quad S_{33}=S_{V} \\
& S_{12}=S_{13}=S_{23}=0 \\
& C S_{11}=\sin \alpha ; \quad C S_{12}=-\cos \alpha ; \quad C S_{13}=0 ; \quad C S_{21}=\cos \alpha \\
& C S_{22}=\sin \alpha ; \quad C S_{23}=0 ; \quad C S_{31}=0 ; \quad C S_{32}=0 ; \quad C S_{33}=1
\end{aligned}
$$

Based on the analysis of the above mentioned mechanism, we need to establish the shear mechanics model of casing damage.For convenience of calculation. Through indoor core test, admitted to study physical and mechanical properties of the rock in the area, get the principal stress value and stress direction and the related mechanical parameters, thus the objective layer tensile and shear strength is calculated. 


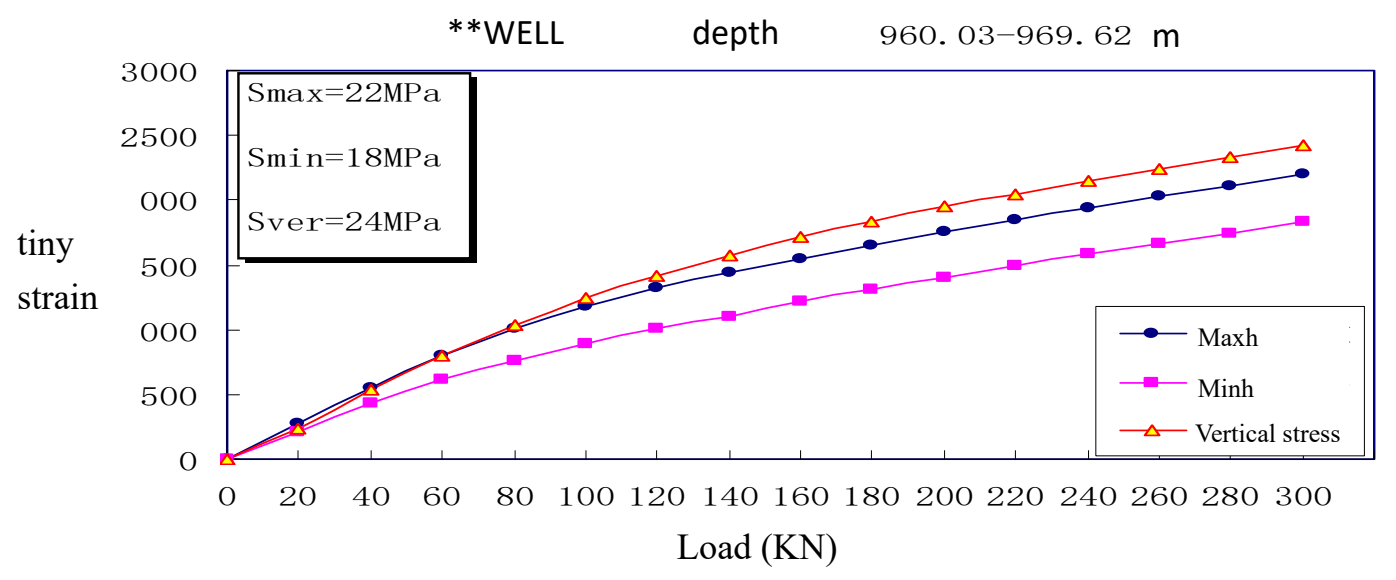

Fig.3calculating principal stress

This model is the most comprehensive currently. Shear mechanical model can be used to judge the stability of the layeror fault under the condition of water injection, to determine the reasonable water injection pressure.

\section{Calculating the critical pressure of water injection in $X$ area}

According to the shear mechanics model of casing damage and the parameters (table 1), calculating the critical pressure of water injection for attitude of stratum in $\mathrm{X}$ area

Tab.1 calculating parameters

\begin{tabular}{|c|c|c|}
\hline & Depth (m) & $900 \mathrm{~m}$ \\
\hline \multirow{4}{*}{ crustal stress } & Maxh (MPa) & 22 \\
\cline { 2 - 3 } & Minh (MPa) & 18 \\
\cline { 2 - 3 } & $\begin{array}{c}\text { Value of vertical stress (MPa) } \\
\text { Direction of horizontal maximum } \\
\text { principal stress (NE) }\end{array}$ & 24 \\
\hline \multirow{2}{*}{ attitude of stratum } & Dip direction (NE) & $120^{\circ}$ \\
\cline { 2 - 3 } & dip angle (degree) & $3-10^{\circ}$ \\
\hline
\end{tabular}

Can be seen from the diagram, when the formation of level or nearly level angle, that is, angle is less than $2^{\circ}$, The formation tendency has little effect on the critical water injection pressure. But when the dip Angle is greater than $2^{\circ}$, the effects is bigger, steep stratigraphic more the greater the effect on the critical injection pressure. 


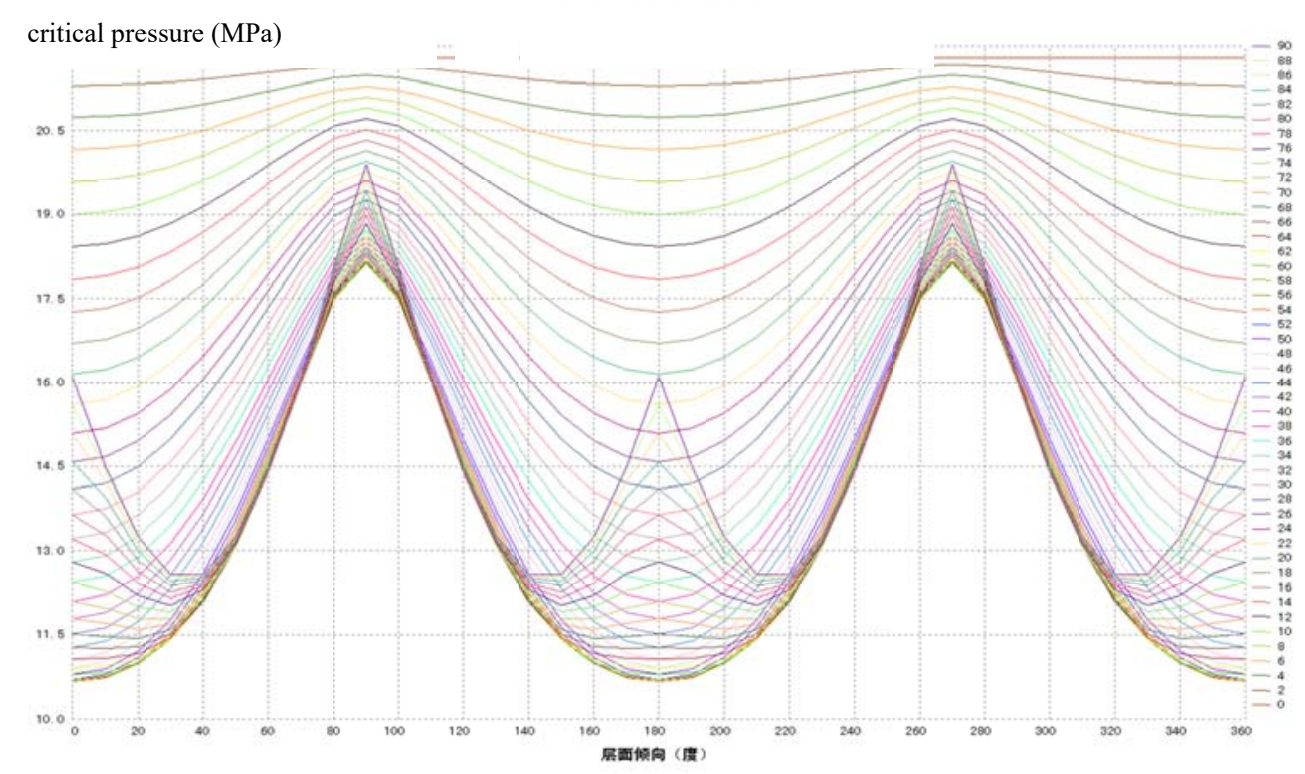

Fig.4critical water injection pressure distribution in different attitude of stratum formation (rectangular)

\section{5 conclusions incline direction (degree)}

1 A-B interlayer is mechanical weak surface, with its tensile strength is only 0.33 MPaon average. And the shear strength is also weak. The numerical results show that the casing damage is not only the weak surface, but also the shear surface which is easy to occur.

2 The lithology of casing damage of A-B interlayer is hard where the fracture development in the casing damage parts, and it is high resistance layer rich in biological fossil.

3 A-B interlayer casing damage mechanics process is as follows: A. Injected water enter into fossil bed; B. wellhead pressure of water injection reached to $10-11.8 \mathrm{MPa}$; $\mathrm{C}$. Under the action of ground stress and dip angle, the instability of the fossil bed leads to the damage of the casing.

\section{References}

[1]Xu Jianjun, Xu Yan-chao, Yan, Li-mei, et.a1. Research on the method of optimal PMU placement. International Journal of Online Engineering, v9, S7, p24-29, 2013

[2] Xu Jian-Jun, Y. Y. Zi., Numerical Modeling for Enhancement of Oil Recovery via Direct Current. International Journal of Applied Mathematics and Statistics, 2013, 43 (13): $318-326$

[3]Longchao, Zhu Jianjun, Xu; Limei, Yan. Research on congestion elimination method of circuit overload and transmission congestion in the internet of things. Multimedia Tools and Applications, p 1-20, June 27, 2016

[4]Yan Limei, Zhu Yusong, Xu Jianjun, et. al. Transmission Lines Modeling Method Based on Fractional Order Calculus Theory. TRANSACTIONS OF CHINA ELECTROTECHNICAL SOCIETY, 2014 , Vol. 29, No. 9:260-268 (In Chinese)

[5]YAN Li-mei, CUI Jia, XU Jian-jun, et.al. Power system state estimation of quadrature Kalman filter based on PMU/SCADA measurements. Electric Machines and Control. 2014, Vol. 18 No. 6, : 78-84. (In Chinese) 
[6]YAN Limei, XIE Yibing, XU Jianjun, et.al. Improved Forward and Backward Substitution in Calculation of Power Distribution Network with Distributed Generation. JOURNAL OF XI' AN JIAOTONG UNIVERSITY, 2013, Vo1. 47, No. 6, p117-123. (In Chinese)

[7]Xu J. J. , Gai D. , Yan L. M. A NEW FAULT IDENTIFICATION AND DIAGNOSIS ON PUMP VALVES OF MEDICAL RECIPROCATING PUMPS. Basic \& Clinical Pharmacology \& Toxicology, 2016, 118 (Supp1. 1), 38-38 